\title{
Front Matter: Volume 12061
}

, "Front Matter: Volume 12061," Proc. SPIE 12061, AOPC 2021: Infrared Device and Infrared Technology, 1206101 (24 November 2021); doi: $10.1117 / 12.2622689$

SPIE. Event: Applied Optics and Photonics China 2021, 2021, Beijing, China 


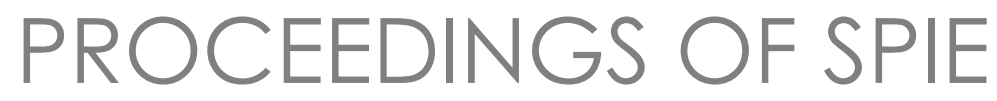

\title{
AOPC 2021: Infrared Device and Infrared Technology
}

\author{
HaiMei Gong \\ Zelin Shi \\ Jin Lu \\ Editors
}

\section{0-22 June 2021 \\ Beijing, China}

Organized by

University of Electronic Science and Technology of China (China)

Science and Technology on Low-light-level Night Vision Laboratory (China)

Science and Technology on Electro-Optical Information Security Control (China)

Nano-Optoelectronics Laboratory, Department of Electronic Engineering, Tsinghua University (China)

Sponsored by

Chinese Society for Optical Engineering (China)

Published by

SPIE 
The papers in this volume were part of the technical conference cited on the cover and title page. Papers were selected and subject to review by the editors and conference program committee. Some conference presentations may not be available for publication. Additional papers and presentation recordings may be available online in the SPIE Digital Library at SPIEDigitalLibrary.org.

The papers reflect the work and thoughts of the authors and are published herein as submitted. The publisher is not responsible for the validity of the information or for any outcomes resulting from reliance thereon.

Please use the following format to cite material from these proceedings:

Author(s), "Title of Paper," in AOPC 202 1: Infrared Device and Infrared Technology, edited by HaiMei Gong, Zelin Shi, Jin Lu, Proc. of SPIE 12061, Seven-digit Article CID Number (DD/MM/YYYY); (DOI URL).

ISSN: 0277-786X

ISSN: 1996-756X (electronic)

ISBN: 9781510649972

ISBN: 9781510649989 (electronic)

Published by

SPIE

P.O. Box 10, Bellingham, Washington 98227-0010 USA

Telephone +1 3606763290 (Pacific Time)

SPIE.org

Copyright (C) 2021 Society of Photo-Optical Instrumentation Engineers (SPIE).

Copying of material in this book for internal or personal use, or for the internal or personal use of specific clients, beyond the fair use provisions granted by the U.S. Copyright Law is authorized by SPIE subject to payment of fees. To obtain permission to use and share articles in this volume, visit Copyright Clearance Center at copyright.com. Other copying for republication, resale, advertising or promotion, or any form of systematic or multiple reproduction of any material in this book is prohibited except with permission in writing from the publisher.

Printed in the United States of America by Curran Associates, Inc., under license from SPIE.

Publication of record for individual papers is online in the SPIE Digital Library.

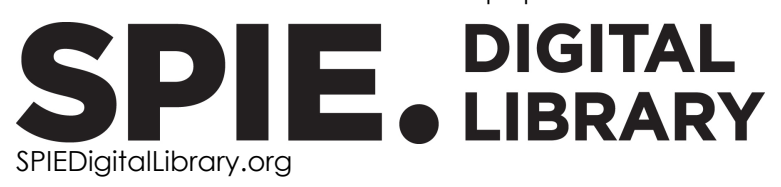

Paper Numbering: A unique citation identifier (CID) number is assigned to each article in the Proceedings of SPIE at the time of publication. Utilization of CIDs allows articles to be fully citable as soon as they are published online, and connects the same identifier to all online and print versions of the publication. SPIE uses a seven-digit CID article numbering system structured as follows:

- The first five digits correspond to the SPIE volume number.

- The last two digits indicate publication order within the volume using a Base 36 numbering system employing both numerals and letters. These two-number sets start with 00, 01, 02, 03, 04, 05, 06, 07, 08, 09, 0A, OB ... 0Z, followed by 10-1Z, 20-2Z, etc. The CID Number appears on each page of the manuscript. 


\section{Contents}

INFRARED DEVICE AND INFRARED TECHNOLOGY

$1206102 \quad$ High-quality reconstruction in non-line-of-sight imaging via transient multiplied photon count data [12061-1]

1206103 A low-cost mid-infrared polarizer with double-sided silica anti-reflection films fabricated using nanoimprint [12061-2]

1206104 Reconfigurable high-order radio frequency filters based on a wide-bandwidth optical frequency comb [12061-3]

1206105 InAsSb/AIAsSb nBn HOT focal plane array [12061-6]

1206106 Design of infrared small-target adaptive detection system based on DSP and FPGA [12061-11]

$1206107 \quad$ High-speed fringe projection profilometry based on convolutional neural network [12061-12]

1206108 Research on the ranging method of point target by monocular vision based on constraints on trajectory and line of sight [12061-13]

1206109 Binocular stereo vision technology based on human visual characteristics [12061-14]

12061 OA Exploration and application of convolutional neural network to improve the quality of DAS voice print machine recognition and acoustic reduction [12061-15]

12061 OB Pose estimation of non-cooperative target based on depth image [12061-16]

12061 OC Adjustable electromagnetically induced transparency based on terahertz metamaterial embedded with vanadium dioxide [12061-17]

12061 OD Estimation method of infrared detection range for reentry target based on signal-to-clutter ratio [12061-18]

12061 OE A real-time local path planning method in complex scenes [12061-19]

12061 OF Modelling effects of GaN HEMTs terahertz detectors with spiral antennas [12061-20]

$120610 G \quad$ Research on nonuniformity correction based on deep learning [12061-21]

$12061 \mathrm{OH} \quad$ VHF coverage analysis for quasi-equatorial Earth satellites [12061-22]

12061 이묘 Design of terahertz IMPATT device [12061-23] 
12061 0J The THz imager instrument for ice cloud remote sensing [12061-24]

12061 OK Method for calibrating heat flow meter for small heat flow [12061-26]

12061 OL Ultra-thin terahertz devices based on Pancharatnam-Berry phase [12061-27]

12061 OM FOV expanded upconversion imaging based on tight focusing system [12061-28]

12061 ON Switchable narrowband THz metasurface filter based on vanadium dioxide [12061-29]

1206100 Research on optical fiber compact terahertz time-domain spectroscopy system and cluster analysis of hyperspectral images [12061-32]

12061 OP Mismatches removal in unmanned aerial vehicle image registration using density based method [12061-33]

$120610 Q$ Design of fast Fourier transform spectrometer in THz atmospheric limb sounder (TALIS) system [12061-35]

12061 OR 3D small-scale object recognition network in cluttered point cloud scenes [12061-40]

12061 OS Infrared thermal imaging high-precision temperature measurement technology [12061-42]

12061 OT Better depth images create better motion recognition [12061-43]

12061 OU 3D topological Dirac semimetal $\left(\mathrm{Zn}_{\mathbf{x}} \mathrm{Cd}_{1-\mathrm{x}}\right)_{3} \mathrm{As} 2 / \mathrm{Sb}_{2} \mathrm{Se}_{3}$ film heterojunction for high performance visible to near-infrared photo detection [12061-44]

12061 OV Prototype for infrared detector front end electronics based on COTS devices under cryogenic temperature [12061-47]

12061 OW Real-time infrared small target search and tracking algorithm based on adaptive track correlation [12061-48]

$120610 X \quad$ Design of an infrared target simulator for military testing [12061-56]

12061 OY Infrared unmanned aerial vehicle detection based on generative adversarial network data augmentation [12061-57]

$120610 Z$ A GAN-based visible and infrared image fusion algorithm [12061-58]

$1206110 \quad$ Inversion of input signal energy using FWHM of output waveform [12061-64]

$1206111 \quad$ Focused micro-lens array design and performance testing [12061-67]

1206112 Analysis of the influence of outer plate inclination on infrared and radar detection of ships at sea [12061-68] 
1206113 Infrared image detail enhancement based on guided filtering with APHE [12061-69]

1206114 Angle measurement method based on axicon lens [12061-70]

1206115 Non-uniformity correction for infrared cameras with variable integration time based on twopoint correction [12061-71]

1206116 Calibration and application of radiometer for low-temperature infrared radiation source [12061-72]

1206117 Design and experimental study for lens working at both room and low temperature [12061-73]

1206118 An adaptive fringe projection method for measuring three-dimensional profile of surface with high reflectivity using sub-pixel coordinate mapping [12061-74]

1206119 A calculation approach for shock layer radiation and transmittance towards hypersonic infrared homing vehicle [12061-76]

12061 1A Multi-wavelength QCL laser system for on-line detection of multi-component gases [12061-77]

12061 1B Terahertz characteristics of amino acids based on microfluidic technology [12061-78]

$120611 \mathrm{C}$ Design of dual-channel projection collimator for dynamic infrared scene projector [12061-79]

12061 1D Analysis of the internal stray radiation in infrared imaging system based on ambient temperature [12061-81]

$120611 \mathrm{E} \quad$ A dual-polarization mode terahertz modulator based on metamaterial and HEMT structures [12061-82]

12061 1F Terahertz spectra of sodium carboxymethyl cellulose and guar gum [12061-84]

$120611 G \quad$ Wavelength modulation spectrometer using interband cascade laser for exhaled breath carbon monoxide measurement [12061-85]

12061 1H Banknotes anti-counterfeiting system based on THz-TDS confocal imaging [12061-89]

$1206111 \quad$ Recent progress in dark current suppression and efficiency enhancement methods for antimonide superlattice detectors [12061-92]

$120611 \mathrm{~J} \quad$ Spectral emissivity measurement based on radiation at multiple temperatures [12061-93]

12061 1K Innovative thermo-mechanical design for large format cryogenic infrared focal plane assembly [12061-94]

12061 1L Sensitive parameters affecting dark current characteristics of SCD [12061-95]

$120611 \mathrm{M}$ Design and research on calibration method of multi-channel self-calibration infrared radiation thermometer [12061-96] 
12061 iN Space-based infrared staring sensor design method integrating detection and information processing technology [12061-97]

1206110 Convergent trinocular stereo measurement model for non-cooperative target [12061-99]

12061 1P High frame frequency dynamic infrared scene projector based on dual-DMD [12061-101]

$120611 Q \quad$ Infrared emission enhancement of a black coating doped with multiwall carbon nanotubes using multi-spraying method [12061-102]

12061 IR InGaAs short wavelength infrared detector based on carrier collection effect [12061-106]

12061 is The method for predicting laser interference image in infrared detection system [12061-107]

12061 IT Study on closed loop frequency tracking circuit of resonant infrared sensor [12061-108]

$120611 \mathrm{U}$ Weak infrared radiation intensity measurement based on extended Duffing oscillator [12061-110]

12061 1V A novel velocity measurement method based on contact image sensor [12061-111]

12061 1W An analytical method for cold optical lens design based on LightTools [12061-112] 